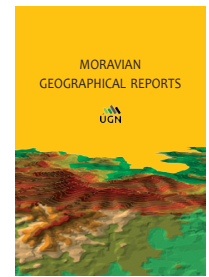

MORAVIAN GEOGRAPHICAL REPORTS

\title{
Citizen science as a new approach in Geography and beyond: Review and reflections
}

\author{
Jakub TROJAN ${ }^{\text {a }}$, Sven SCHADE ${ }^{\text {b }}$, Rob LEMMENS ${ }^{\text {c }}$, Bohumil FRANTÁL ${ }^{\text {a }}$
}

\begin{abstract}
Issues related to the evolving role of citizen science and open science are reviewed and discussed in this article. We focus on the changing approaches to science, research and development related to the turn to openness and transparency, which has made science more open and inclusive, even for non-researchers. Reproducible and collaborative research, which is driven by the open access principles, involves citizens in many research fields. The article shows how international support is pushing citizen science forward, and how citizens' involvement is becoming more important. A basic scientometric analysis (based on the Web of Science Core Collection as the source of peer reviewed articles) provides a first insight into the diffusion of the citizen science concept in the field of Geography, mapping the growth of citizen science articles over time, the spectrum of geographical journals that publish them, and their citation rate compared to other scientific disciplines. The authors also discuss future challenges of citizen science and its potential, which for the time being seems to be not fully utilized in some fields, including geographical research.
\end{abstract}

Keywords: citizen science; open science; open-access; neo-geography; scientometric analysis

Article history: Received 20 September 2019, Accepted 12 December 2019, Published 31 December 2019

\section{Open science as an impetus for the citizens}

How scientific research is conducted has evolved over many centuries. Amongst several transitions, significant changes have taken place with respect to research methods, openness and the interactions of science and society. Since the $17^{\text {th }}$ century, when the prestige of noble patrons caused scientists to perform their research in secrecy, scientists have found ways to collaborate and disclose their results and to obtain acknowledgements for their work (David, 2007). Despite the fact that this has led to a rich culture of journals and the foundations of copyright, it restricted access by society at large. With the evolution of scientific societies during the $19^{\text {th }}$ century, however, we can see a movement taking place towards a more 'open' science through public domain thinking and the open access paradigm of the second half of the $20^{\text {th }}$ century (Green, 2017).
The concept of open science can be interpreted in many ways, depending on how the word 'open' is understood and whether this refers to the process, means, results, etc. of science. A rather comprehensive definition is provided by Foster (2016: 1), who describes "open science as the movement to make scientific research, data and dissemination accessible to all levels of an inquiring society".

Although Foster's definition implies an inclusion of process arrangements in open science, the Foster taxonomy puts these at a higher level, i.e., Responsible Research and Innovation, under which label we can find Open Science, Education, Governance, Gender Policy, Ethics and Public Engagement (Participatory research, Citizen science, etc) (cf. Foster, 2016). Several initiatives have started to let organisations stimulate open science in practice, on

\footnotetext{
${ }^{1}$ see https://osf.io

2 https://www.openscience.nl
}

\footnotetext{
${ }^{a}$ Institute of Geonics of the Czech Academy of Sciences, Department of Environmental Geography, Brno, Czech Republic (*corresponding author: J. Trojan, e-mail: jakub.trojan@ugn.cas.cz)

${ }^{\mathrm{b}}$ European Commission, Joint Research Centre, Ispra, Italy

c University of Twente, Faculty of Geo-Information Science and Earth Observation, Department of Geoinformation Processing, Enschede, The Netherlands.
} 
a national level (e.g., US Open Science Framework ${ }^{1}$, Dutch Open Science Platform ${ }^{2}$, and at the international level (e.g., the EU Open Science Policy Platform ${ }^{3}$ ).

Obviously, in recent years, information and communication technologies have opened up ways for collaboration and sharing research data in many new ways. Not only have tools such as mobile communication and online services become available for collaborative research, but the web has made science more digestible for society at large. On the other hand, it has also forced scientists to adapt their processes of knowledge creation and dissemination to an environment with peer-researchers and software-based services, in which they have less control (Bartling and Friesike, 2014). Moreover, the myriad of communication channels, including social media, is facilitating an unprecedented outreach, but at the same time causes a publication abundance in which quality metrics are not always easily set (see e.g., Mirowski, 2018; Gadermaier et al., 2018; Specht and Lewandowski, 2018).

\section{Open access, reproducible and collaborative research}

An important condition for the open science movement lies in open access to research materials, which can be achieved through open access journals and self-archiving. Besides the articles and findings themselves, the open data symbolizing common outputs from the citizen science projects are very important. Whereas scientific articles published under the open access principle are useful mainly for other researchers, scientific data published as open data could also be valuable for public administration/government, citizens conducting their own research, media, etc. Public open data without any subjective comments might be more unbiased than articles with conclusions published as open access: in this case, we need to point out some abuse of open access by predatory journals, see for example, Sorokowski, 2017 or Fell, 2019. The importance of open access, however, is a key aspect of the process of opening science.

Fundamental to clear open access rulings is the availability of licencing schemes. With the advent of open source software, license options are made available that support the reuse of the software code. With respect to open content in general, a simple but effective scheme has been developed through the realm of the Creative Commons, which can be applied to a variety of content types, such as research data, images and publications (Frieseke, 2014). In addition to accessing research materials, scientists should be able to verify existing research results in order to reuse them and innovate. For this purpose, the FAIR guiding principles (Findable, Accessible, Interoperable, Reusable) have been established (Wilkinson et al., 2016), serving to enhance the reliability and reproducibility of research.

Whereas the open science movement and stimuli from funding agencies are leading to scientists' collaboration in project research consortia, the engagement of nonacademics in the knowledge creation process is growing (Dickinson et al., 2012) and can be attributed to the open science movement. Such engagement can range from a single contribution of measurement to active participation in the scientific process (Haklay, 2013). Hecker et al. (2018) state that citizen science practitioners have an acute awareness about the societal relevance of their participation. This provides a great opportunity for scientists to put their research into a societal context.

Although there are some concerns about open science, such as quality control issues, platform domination by larger technology players and publishers (Mirowski, 2018), there are developments that take open science a step further, such as open data policies and new interoperable representations of knowledge (Albagli et al., 2015). An important task for all researchers is to educate the new open scientists on topics of quality, reusability and responsibility.

\section{Towards citizen science}

Citizen science appears to be a new term but it is actually a relatively old practice (see e.g., Eitzel, et al., 2017). The term itself incorporates diverse forms of cooperation and interaction among volunteers from the public, carried out in order to benefit society and the environment. Although this term was not adequately established in the scientific literature until the 1990s (Bonney et al., 2009), similar interactions had existed long before. One of the typical fields in which citizens participated substantially to scientific research is astronomy, where amateur astronomers collectively observed a variety of celestial objects and phenomena (Mims, 1999). For such activities, the term citizen science created a new framework and offered specified definitions and contents for already existing phenomena, conducted mostly with the help of modern information technologies. Some examples of these trends can be seen as: from simply collecting data about bird strikes around 1880 (Droege, 2007) to advanced odour sensing, for example via the D-NOSES project ${ }^{4}$ funded by the European Union's Horizon 2020 Science with \& for Society (SwafS) ${ }^{5}$ call. Opening science, accessing modern technologies and raising public awareness, are critical factors for empowering citizen scientists and academics.

Many things have changed since the end of the $20^{\text {th }}$ century. Opening science led to the increased engagement of citizens, as well as thoughtful acceptance of data sets coming from public participation in research. If we compare articles using public participation - in any format of its meaning, from collecting data and serving people as sensors, to public participation in research design and outputs analyses from the past decades to the present, papers increasingly rely on the participation of citizen scientists (Follet and Strezov, 2015; Kullenberg and Kasperowski, 2016). This trend holds valid especially for natural and environmental sciences (Theobaldt et al., 2015), and applies to a large degree to research projects that require large amounts of data. The resulting data sets are usually published as well, for example, as an appendix to the original article, as downloadable files or in easliy-accessible databases. Notably, the integration of citizen science principles into modern (open) science has been spearheaded by ornithologists (see for example, the activities of the Cornell Lab of Ornithology in $\mathrm{US}^{6}$, or the Czech Ornithologists Society ${ }^{7}$ in the Czech

\footnotetext{
${ }^{3}$ https://ec.europa.eu/research/openscience/

${ }^{4}$ https://dnoses.eu/

${ }^{5}$ https://ec.europa.eu/research/swafs/index.cfm

${ }^{6}$ https://www.birds.cornell.edu/citizenscience/

${ }^{7}$ https://www.birdlife.cz/en/
} 
context). Bird watching has become a global phenomenon, where thousands of people are observing birds and helping scientists in research in this bio-geographical field (Devictor et al., 2010).

The movement of empowering citizen scientists appeared to have progressed faster in the European "western countries" compared to Central and Eastern European countries. More details for the Czech case are provided by one of the papers in this issue (Duží et al., 2019). The uneven production of knowledge with citizen scientists were also described by Irwin (1995). This "delay" does not mean that citizen science does not exist in those countries - it is just less visible (see the research conducted, for example, by Balint Balazs for Central and Eastern European countries, or the activities conducted by the Czech Academy of Sciences in its Institute of Botany ${ }^{8}$ and Institute of Geonics ${ }^{9}$ ). Such empowerment is boosted by technological development. Technologies have increased the options for citizen science in enabling people to participate in more and more research fields. Technologies enable, among other aspects, the social sciences to carry out citizen science activities. A good example comes from the history of fine art, where digitalisations of the personal papers and letters of British-born émigré artists enabled the development of an online transcription tool (hosted in the Zooniverse platform ${ }^{10}$ ). In this case, volunteers could study and transcribe the digital archives. The popularity of Zooniverse itself - along with other platforms serving as repositories for citizen science projects, such as SciStarter or the Atlas of Living Australia - is strongly connected to the ubiquitous Internet connections and growing market of mobile technologies. Global repositories and platforms attract both researchers and citizens to connect mutually. As a natural outcome, one witnesses countless combinations of open science principles, new technologies and citizen science approaches, which lead to valuable projects based on building instruments to gather data for their own experiments (Baden et al., 2015). These activities are reinforced by continuing movements that are related to open software and open hardware, such as 3D printing (Pearce, 2012).

While the number of public participants in science and citizen science-based projects is increasing (despite the fact that many of them do not have long term engagement), the initiatives dealing with national and global coordination of public participation in research is becoming more critical. Leading organizations such as the American Citizen Science Association $(\mathrm{CSA})^{11}$, the Australian Citizen Science Association $(\mathrm{ACSA})^{12}$, the European Citizen Science Association $(\mathrm{ECSA})^{13}$, and several national and regional associations are proposing knowledge exchange, increased interoperability and improved standardization (for example, the 10 principles of Citizen Science made by ECSA (ESCA, 2015). These activities continuously help to improve the society-science-policy interface.

\section{Citizen science in Europe - cooperation, networking and research}

The major and traditional European-level support for citizen science originated from the EU-funded science and society programs, such as SwafS call (see footnote 5) and in the earlier FP7 and current Horizon 2020 programmes. Some examples are CitieS-Health ${ }^{14}$ (on urban pollution), D-NOSES $^{15}$ (on odour pollution control), WeObserve ${ }^{16}$ (on environmental monitoring), Doing It Together Science $\left(\right.$ DITOs) ${ }^{17}$ (on active involvement of citizens in citizen science), LandSense ${ }^{18}$ (on the use of satellite imagery for environmental decision making), GroundTruth2.0 ${ }^{19}$ (on sustainable implementation of citizen observatories), and EU-Citizen.Science ${ }^{20}$ (tasked to set up a European Citizen Science Platform). Successful citizen science proposals have also appeared in related projects, such as the Collaborative Awareness Platforms (CAPs, examples include Making Sense $^{21}$, and $\mathrm{CAPTOR}^{22}$ ), and most recently also in the area of open science and the European Open Science Cloud $(\mathrm{EOSC})^{23}$

In terms of application areas, citizen science already feeds particularly into environment-related policy (Bio Innovation Service, 2018), e.g., $\mathrm{LIFE}^{24}$. It is not only carried out in projects (as in the LIFE program) but also contributes scientific evidence to policy making, as for example, for farmland and agricultural birds, and marine litter. A recent study (Bio Innovation Service, 2018) identified more than 500 citizen science projects that are related to environmental policy (see also the data catalogue ${ }^{25}$ and Citizen Science Explorer ${ }^{26}$ offered by the European Commission's Joint Research Centre (JRC). Efforts are underway to increase policy relevance and impact (Schade et al., 2017a). The promotion of the wider use

\footnotetext{
${ }^{8}$ https://www.ibot.cas.cz/en/public-relations/citizen-science/

${ }^{9} \mathrm{http}: / /$ www.citizenscience.cz/

${ }^{10} \mathrm{https}: / /$ www.zooniverse.org/

${ }^{11} \mathrm{https}: / /$ www.citizenscience.org/

$12 \mathrm{https} / /$ citizenscience.org.au/

$13 \mathrm{https}$ ://ecsa.citizen-science.net/

${ }^{14} \mathrm{http} / / /$ citieshealth.eu/

${ }^{15} \mathrm{https} / / /$ dnoses.eu/

${ }^{16} \mathrm{https}: / /$ www.weobserve.eu/

${ }^{17} \mathrm{http}: / /$ togetherscience.eu/

${ }^{18} \mathrm{https} / / /$ landsense.eu/

${ }^{19}$ https://gt20.eu/

${ }^{20} \mathrm{http}: / /$ eu-citizen.science/

${ }^{21} \mathrm{http}$ ://making-sense.eu/

${ }^{22}$ https://www.captor-project.eu

${ }^{23}$ https://ec.europa.eu/research/openscience/index.cfm?pg=open-science-cloud\#

${ }^{24} \mathrm{https}$ ://ec.europa.eu/easme/en/life

${ }^{25}$ https://data.jrc.ec.europa.eu/

${ }^{26}$ https://ec-jrc.github.io/citsci-explorer/
} 
of citizen science to complement environmental reporting is one of ten actions which the European Commission has adopted to achieve this goal ${ }^{27}$. Wider discussions related to citizen science data are, for example, supported by a recently published community page ${ }^{28}$, hosted also by the JRC.

An important development has been the initiation (in 2014) and the subsequent evolution of ECSA, which is also supported by the EU. In addition to being a network of researchers, ECSA actively supports project initiatives and the development of the ideas behind open science. ECSA cooperates with the US-based CSA, and with ACSA.

In relation to citizen science, several projects have fostered cooperation in the field of volunteered geoinformation generation (often abbreviated as VGI). In current participative research, VGI plays a major role (Sui et al., 2012). Some examples of the EU efforts in fostering VGI within citizen science are the COST Action IC1203 ENERGIC $^{29}$ (European Network Exploring Research into Geospatial Information Crowdsourcing: software and methodologies for harnessing geographic information from the crowd), and COST Action project TD1202 - Mapping and the Citizen Sensor ${ }^{30}$. Each project resulted in the publication of a book, covering the research performed, (see, respectively, Capineri et al., 2016 and Foody et al., 2017) Currently, a cross-cutting COST Action on citizen science ${ }^{31}$ (CA15212) aims to integrate a wide spectrum of stakeholders to employ citizen science for social innovation and socioecological transition. This will be performed in six working groups, which cover aspects of the scientific quality of citizen science, synergies with education, the society-science-policy interface, the role of citizen science for civil society, data standardization and interoperability and other cross-cutting relevant topics. Other COST actions involve more specialised fields, such as COST Action Alien-CSI (CA17122): Increasing understanding of alien species through citizen science ${ }^{32}$.

As an emerging topic, many European national initiatives recognized the importance of a consolidated central portal. Thus, application portals have been set up over the last 15 years: notably in Austria ${ }^{33}$, Germany ${ }^{34}$, Spain ${ }^{35}$, Belgium $^{36}$, The Netherlands ${ }^{37}$, and the Czech Republic ${ }^{38}$. These mechanisms stimulate citizens to observe and learn and often result in data and mobile apps. Though many of these are very useful within each project, the challenge is to make them reusable across project initiatives and reproducible in the sense of open science (Schade et al., 2017b).

\section{Citizen science and Geography}

Kerski (2015) has emphasized that new converging global trends, including geoawareness, geoenablement, geotechnologies, citizen science and storytelling - all have the potential to offer geography world-wide attention (from education and society) that may be unprecedented in the history of the discipline. Issues which have been central to Geography are now part of the global consciousness, and many tools and data sets that were formerly used and examined only by geographers and other earth and environmental scientists, are now in the hands of the general public (Kerski, 2015: 14). The term "neo-geography" (see Turner, who championed the term in 2006) has also been implicated in this context (see e.g., Wilson and Graham, 2013; Leszczynski, 2014).

In an empirical investigation, we found (as of November 30, 2019) that the Web of Science (WOS) Core Collection included 2,870 articles that included "citizen science" in the Topic category (i.e., the title, abstract, author keywords, and/or keywords plus). Journals covered in the Geography category (according to the WOS classification) have published to date a total of 88 of these articles, which is slightly more than $3 \%$ of all articles on citizen science in the WOS database (see Fig. 1).

We realise that such a selection and subsequent analysis has clear limitations, because we have used the "basic search" method without applying any extra inclusion and/or exclusion criteria, as used by some previous studies (Follett and Strezov, 2015; Kullenberg and Kasperowski, 2016). As a result, some papers could have been omitted because they do not use the exact term "citizen science", even though they could be dealing with some kind of citizen science research while containing related terms, such as for example, volunteered geographic information, neo-geography, or citizen geography. This issue is linked to the prevalent problem of multiple meanings of the concept itself, and the use of alternative terms within different scientific disciplines and geopolitical contexts (see e.g., Eitzel, et al., 2017). Our aim here, however, was not to conduct a precise scientometric analysis but to provide a first insight into the diffusion of the citizen science concept in the field of Geography. The results presented below are based on an analysis excluding articles published during 2019 , because this year was not complete at the time of writing this paper.

The first article published in a geographical journal that included "citizen science" in its content (specifically in the author's keywords) was "Building capacity for environmental management: Local knowledge and rehabilitation on the Gippsland Red Gum Plains" (Measham, 2007, in the Australian Geographer). Geography is still among the top ten scientific disciplines (according to the WOS categorization) dealing with citizen science, even though the share of geographic journals in publishing citizen science articles has been quite volatile over recent years (see Fig. 2). According to an earlier study by Kullenberg and Kasperowski (2016),

\footnotetext{
${ }^{27} \mathrm{https}$ ://ec.europa.eu/environment/legal/reporting/fc_actions_en.htm

${ }^{28} \mathrm{https} / / / \mathrm{ec}$. europa.eu/jrc/communities/en/community/citizensdata

${ }^{29} \mathrm{http}$ ://vgibox.eu/

${ }^{30} \mathrm{https} / / /$ www.cost.eu/publications/mapping-and-the-citizen-sensor/

${ }^{31} \mathrm{https}: / / \mathrm{cs}-\mathrm{eu} . \mathrm{net} /$

${ }^{32}$ https://alien-csi.eu/

${ }^{33} \mathrm{https}: / /$ www.citizen-science.at/

${ }^{34} \mathrm{http}: / /$ www.citizen-science-germany.de/

${ }^{35} \mathrm{https} / / /$ natusfera.gbif.es/?locale $=\mathrm{en}$

${ }^{36} \mathrm{https}: / /$ www.scivil.be/en

${ }^{37} \mathrm{https}: / /$ waag.org/en

${ }^{38} \mathrm{http}: / /$ www.citizenscience.cz/
} 


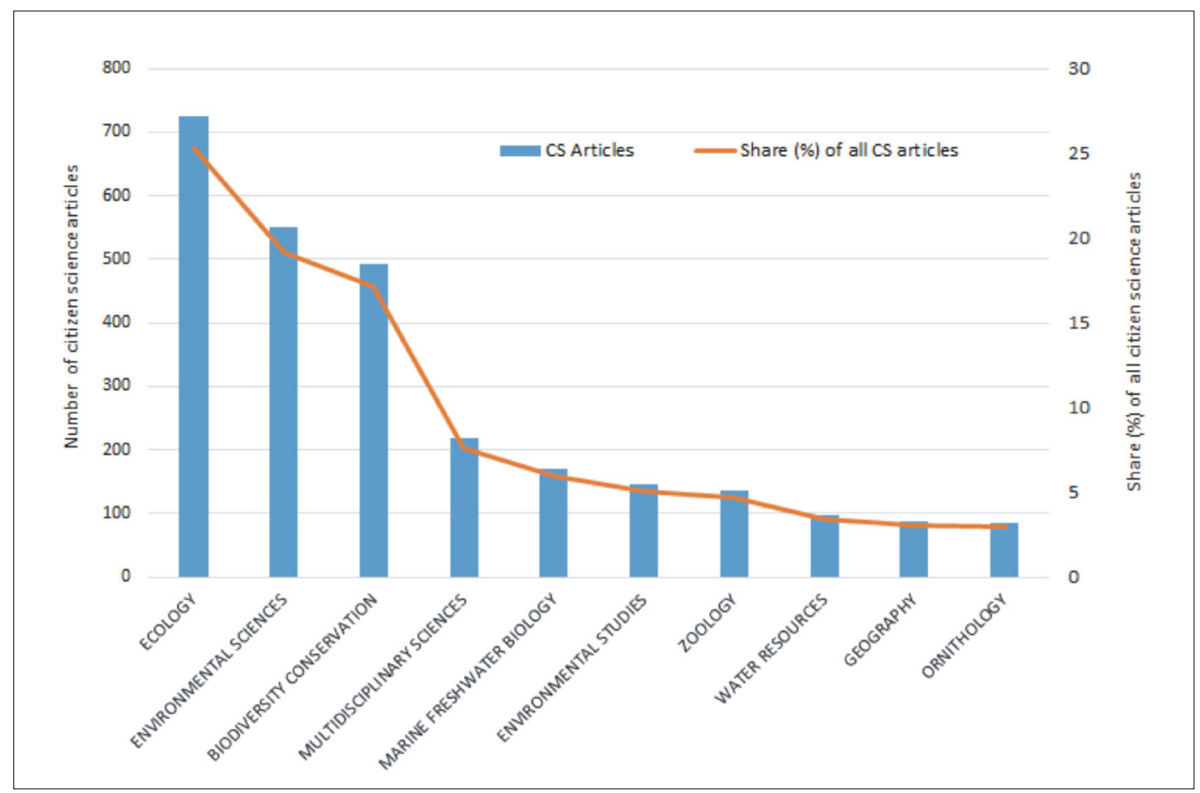

Fig. 1: The number of "citizen science" articles and the proportion of all citizen science articles according to Web of Science categories as of November 30, 2019 (Note: The graph includes only the top ten categories) Source: authors' elaboration based on WOS/Clarivate Analytics data (2019)

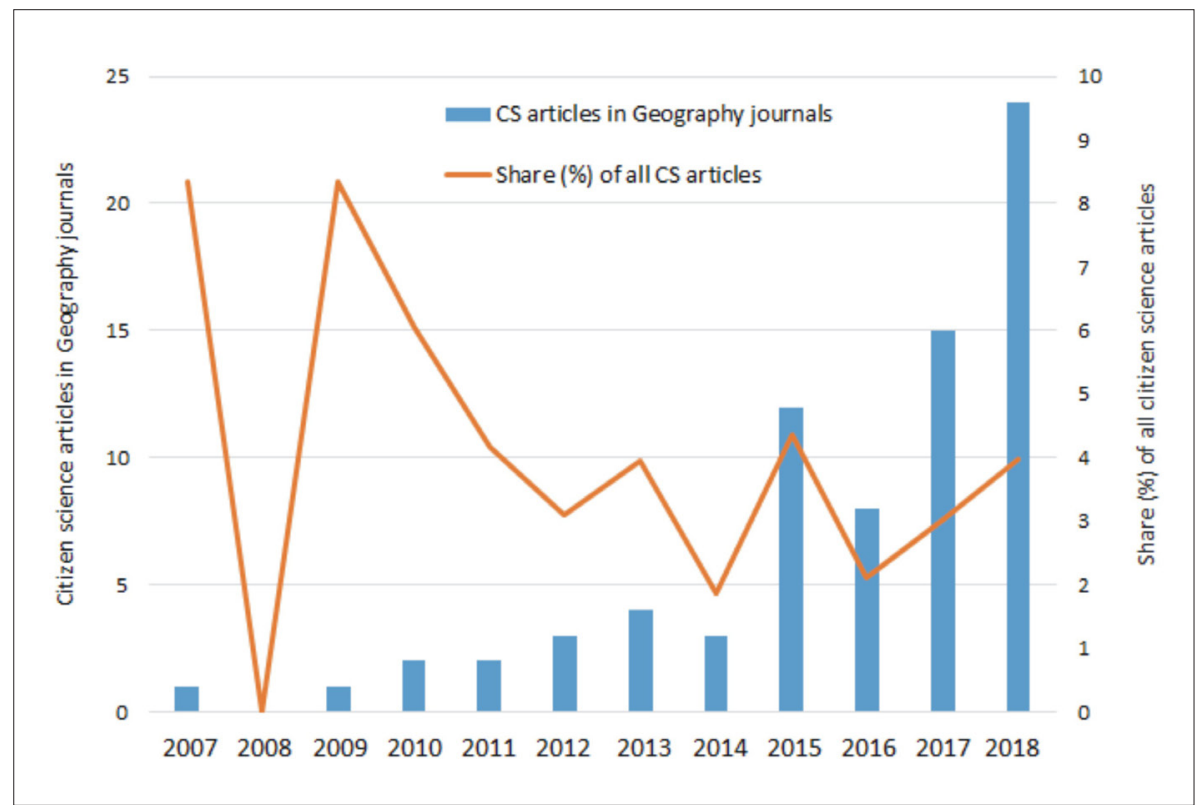

Fig. 2: The number of citizen science articles in Geography journals and the share of all citizen science articles for the category according to Web of Science categories (2007-2018)

Source: authors' elaboration based on WOS/Clarivate Analytics data

Geography was equal in third place among disciplines in the number of published citizen science articles (after Ecology and Environmental Sciences), but it has been overtaken in recent years by Biodiversity Conservation, Marine Freshwater Biology, Zoology and Water Resources categories. The articles in geographical journals, however, show a similar trend to the articles in other scientific disciplines, in that research on methodology, the quality and reliability of data and validation techniques, preceded the rise of the publications on empirical research outcomes based on citizen science methods (see Follett and Strezov, 2015).

It may seem that Geography does not fully utilize its potential for publishing citizen science research at this time (see e.g., Connors, Lei and Kelly, 2012), or that geographical journals are not so open to this type of article and/or that authors prefer publishing in journals in other fields or use different publishing models (Follett and Strezov, 2015). Another interpretation may be that geographers use different terminology.

A basic analysis of authors' keywords used in citizen science articles in geographical journals revealed that "crowdsourcing" and "volunteered geographic information" (VGI) are among the most frequent keywords (see Fig. 3) and, in fact, these two terms are generally more widespread in geographic journals than the "citizen science" term. As emphasized by Cooper et al. (2017), the concepts of volunteered geographic information, crowdsourcing, neogeography and citizen science are sometimes confused with 


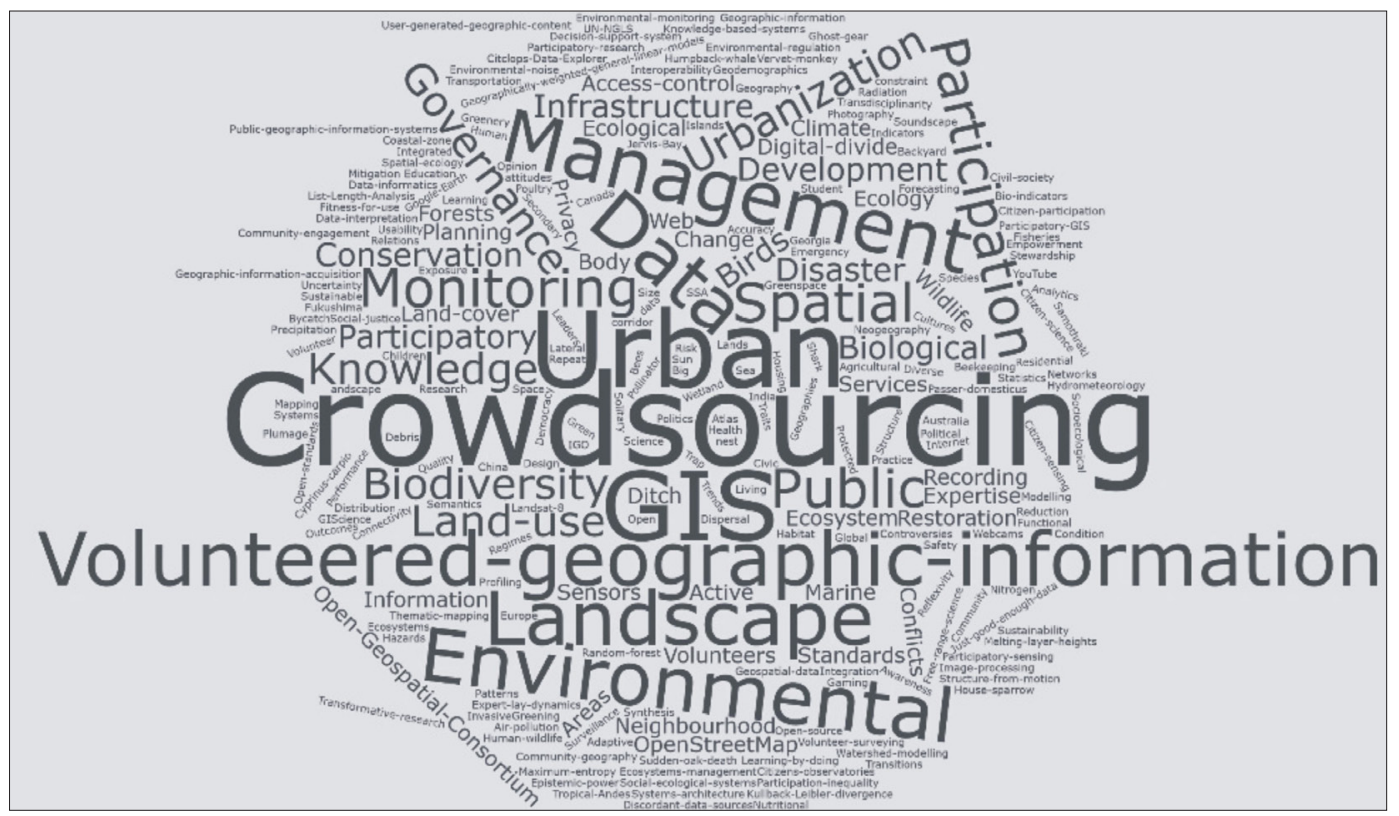

Fig. 3: A collage (word-cloud) of the most frequent authors' keywords assigned to citizen science papers in Geography journals. Source: data from WOS / Clarivate Analytics (2019); authors' elaboration using Free Wordcloud generator (www.wordclouds.com)

one another - even though each of these concepts has unique characteristics and even though they can overlap. Cooper and colleagues (2017) provide some practical examples of citizen science that are neither neo-geography, VGI, nor crowdsourcing, and examples of neo-geography that are neither VGI nor citizen science.

Nevertheless, the use of the citizen science approach relies on a wider acceptance of this method by the scientific community and academic journals. Gadermaier et al. (2018) outlined five factors that influence the probability of publication using citizen science data in open-accessed peer-reviewed scientific journals. These factors include: (i) funding to cover publication costs; (ii) quality, quantity and scientific novelty of the data; (iii) recommendations to acknowledge the contributions of citizen scientists in scientific, peer-reviewed publications; (iv) citizen scientists' preference for the hands-on experience over the product (publication); and (v) bias among scientists for certain data sources and scientific jargon (Gadermaier et al., 2018: 1). Citizen science papers to date have been published in a total of 33 geographical journals, the largest proportion for the journal Landscape and Urban Planning (see Tab. 1).
One third of all papers have been published as open-access (including the first and the third most cited papers), and the open-access papers have slightly higher average citations per article (14.5) than not open-accessed articles (12.5). It may be interesting to compare the average citations of citizen science papers in Geography journals with other categories (for the same range of publication years): the average citations of citizen science articles in Ecology journals is 22.4; 19.9 in Environmental Sciences; 17.7 in Multidisciplinary Sciences; 14.4 in Environmental Studies; (only) 10.5 in Marine Freshwater Biology; 6.8 in Zoology; and 6.2 in Ornithology. The citation rate seems to reflect the more specialised focus of a specific discipline. The top ten most cited papers on citizen science in Geography journals are listed in Table 2.

With respect to the overall share of countries in publishing citizen science research in Geography, authors from the USA (participating in 28 articles), UK (23 articles), Australia (9 articles) and Germany (8 articles) are most represented. Authors from Austria and Canada authored and/or coauthored four articles, and authors from other countries presented in the chart (see Figure 4) participated on two

\begin{tabular}{cllc}
\hline Rank & Journal & Publisher & No. of articles \\
\hline 1 & Landscape and Urban Planning & Elsevier, Netherlands & 16 \\
2 & International Journal of Spatial Data Infrastructures Research* & European Commission, Italy & 7 \\
3 & Transactions in GIS & Wiley, USA & 7 \\
4 & Annals of the American Association of Geographers & Taylor \& Francis Ltd, England & 6 \\
5 & International Journal of Geographical Information Science & Taylor \& Francis Ltd, England & 5 \\
6 & Applied Geography & Elsevier Sci Ltd, England & 4 \\
7 & Cartography and Geographic Information Science & Taylor \& Francis Inc, USA & 4 \\
8 & Computers Environment and Urban Systems & Elsevier Sci Ltd, England & 4 \\
9 & Earth Systems Data and Models & American Geophysical Union & 4 \\
10 & Global Environmental Change & Elsevier Sci Ltd, England & 4 \\
\hline
\end{tabular}

Tab. 1: The top 10 source journals in Geography for citizen science articles (*Journal covered in the Emerging Sources Citation Index). Source: authors' elaboration based on WOS / Clarivate Analytics data (2019) 
or three articles. The category "others" includes authors from other eight countries (Bolivia, Brazil, Czech Republic, Denmark, Finland, Greece, Japan and Nigeria) who participated in one article.

As examples of 'good practice' in the citizen science approach in the field of Geography we could list several projects (see Tab. 3). Some of the projects redefined the geographical field - as an example, OpenStreetMap brings a new look to map creation and usage in real time, including many derivatives from the original cartographic basemaps (Haklay and Weber, 2008).

Another global community-driven project, FreshWater Watch led by the Earthwatch Institute, has engaged over 9,000 volunteers in collecting 20,000 water samples

\section{Rank Article}

Total citations

1 Ahern, J. et al. (2014): The concept of ecosystem services in adaptive urban planning and design: A framework for supporting innovation. Landscape and Urban Planning, 125: 254-259.

2 Connors, J. P. et al. (2012): Citizen science in the age of neo-geography: Utilizing volunteered geographic information for environmental monitoring. Annals of the Association of American Geographers, 102(6): 1267-1289.

3 Foody, G. M., et al. (2013): Assessing the accuracy of volunteered geographic information arising from multiple contributors to an internet based collaborative project. Transactions in GIS, 17(6): 847-860.

4 Newman, G., et al. (2010): User-friendly web mapping: lessons from a citizen science website. International Journal of Geographical Information Science, 24(12): 1851-1869.

$5 \quad$ Strohbach, M. W. et al. (2013): Are small greening areas enhancing bird diversity? Insights from communitydriven greening projects in Boston. Landscape and Urban Planning, 114: 69-79.

6 Robinson, L. M. et al. (2015): Rapid assessment of an ocean warming hotspot reveals "high" confidence in potential species' range extensions. Global Environmental Change, 31: 28-37.

7 Johnson, M. F. et al. (2014): Network environmentalism: Citizen scientists as agents for environmental advocacy. Global Environmental Change, 29: 235-245.

8 Lawrence, A. (2009): The first cuckoo in winter: phenology, recording, credibility and meaning in Britain Global Environmental Change, 19(2): 173-179.

9 Johnson, B. A., Iizuka, K. (2016): Integrating OpenStreetMap crowdsourced data and Landsat time-series imagery for rapid land use/land cover (LULC) mapping: Case study of the Laguna de Bay area of the Philippines. Applied Geography, 67: 140-149.

10 Bruce, E., et al. (2014): Distribution patterns of migrating humpback whales (Megaptera novaeangliae) in Jervis Bay, Australia: A spatial analysis using geographical citizen science data. Applied Geography, 54: 83-95.

Tab. 2: The top 10 cited citizen science articles in Geography journals Source: authors' elaboration based on WOS / Clarivate Analytics data (2019)

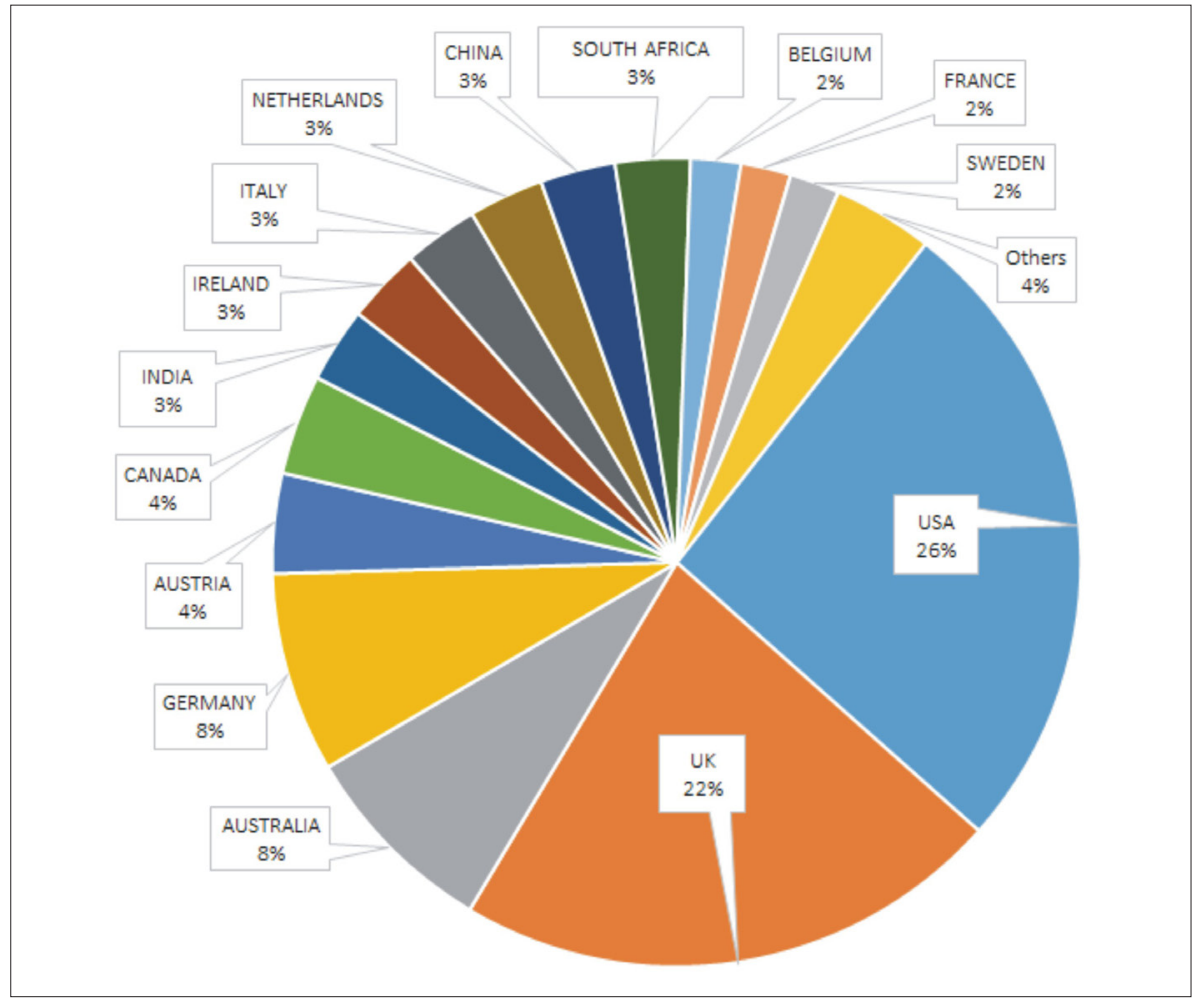

Fig. 4: Share of authors of citizen science articles in Geography journals according to authors' affiliation. Source: authors' elaboration based on WOS/Clarivate Analytics data (2019) 
since 2013 (Bio Innovation Service, 2018). Data collected in this project complement environmental agency monitoring efforts by filling in gaps in spatial and temporal coverage and water body types (Hadj-Hammou et al., 2017). More random examples from the citizen science databases can be found in Table 3.

\section{Current trends and challenges in citizen science}

Across the globe - and especially in Europe - citizen science is applied at different geographic scales, covering a vibrant and ever-expanding set of thematic domains. At the same time that we witness the emerging diversity of approaches, citizen science has also become increasingly recognized, and the interest in applying citizen science solutions continue to emerge from many different fields of science, society and government. This interest might go as far as assuming that citizen science could be the golden solution to resolve the challenges of post-normal science and post-truth politics. While this evolving landscape and acknowledgement leads to new opportunities of transferring knowledge between geographic regions and across stakeholders, it also challenges methods and tools to manage expectations, and to avoid reinventions, the duplication of funding, or potential miss-use due to overexcitement and missing guidance and capacities.

To meet these new challenges, there is an ongoing movement to establish a dense network of citizen science associations and partnerships. National coordination is paired with continental and even global structures. In addition to the above-mentioned examples at the national and European level, support is also provided by the Citizen Science Global Partnership ${ }^{39}$.

Further, organisations such as the Global Biodiversity Information Facility (GBIF) ${ }^{40}$ help coordinate the citizen science community in addressing biodiversity-related matters at the international level. Given that citizen science associations are established in Asia and Africa, too, this network of networks provides a solid ground for knowledge sharing and well-coordinated activities across the entire planet.
Regardless, it remains crucial to see how the regional and national networks, in particular, will respond to the diverse societal, economic and environmental needs, and how they will adopt citizen science in their respective cultural and governmental settings. Particular care will have to be taken in recognising the conditions under which a citizen science activity succeeded in one country (or even one city), and to understand which mechanisms can be applied elsewhere.

At present, discussions on what might qualify as 'citizen science' very much depend on parameters such as the nature of participatory culture, trust in governments and available funding. A significant challenge will be the reuse of shared knowledge and its adoption in a way that suits local contexts. The evolution of citizen science to fit (or possibly innovate) existing knowledge structures and markets will be very different depending on geographic location - in Japan, for example, compared to Ecuador or Sweden (or more regionally in Nairobi, Kenya). It remains to be seen how citizen science will grow and in what ways it will evolve in different parts of the world. In order to better understand these effects and support the future evolution of citizen science, it will be essential to advance the methods and tools to assess the impacts of citizen science on society (individuals and communities), science, governmental policy and the economy.

Regardless of local and regional diversities, the citizen science community has come a long way in achieving technical and semantic interoperability. Especially in the area of biodiversity research and geospatial information, good progress could be made in close collaborations with Biodiversity Information Standards (TDWG ${ }^{41}$ and the Open Geospatial Consortium $(\mathrm{OGC})^{42}$, respectively. Nevertheless, although guidance and recommendations become available, the exploitation of the material for different citizen science user groups remains to be improved. The same condition holds for useful, useable and used standards-based tools. Whereas this challenge might be more controlled within one thematic area (e.g., biodiversity), it becomes more challenging when crosscutting topics - such as situations where the management and processing of geographic information - are considered.

\begin{tabular}{ll}
\hline Project name & Goal / Task \\
\hline Narrative Atlas & Connect, Collaborate and Create Solutions for the SDGs \\
GLOBE Observer: Trees & Observe trees to understand changes in biomass and effects on the carbon cycle \\
GLOBE Observer: Land Cover & Photograph and classify land cover and share the data with NASA \\
The National Map Corps & Update and verify man-made structures data for the USGS \\
Raspberry Shake & Monitor Earth motion and seismic activity around the globe \\
Hush City & To empower people to identify and evaluate quiet areas in cities \\
Landslide Reporter & Build open global landslide data for science and decision-making \\
ISeeChange & Connecting communities to investigate weather and climate change \\
Stream Selfie & Map streams across the country and start testing the waters \\
City Nature Challenge & Document urban biodiversity \\
\hline
\end{tabular}

Tab. 3: Examples of projects from the "Geography" category on SciStarter.com Source: authors' elaboration based on SciStarter.com data (as of November 30, 2019)

\footnotetext{
${ }^{39} \mathrm{http}: / /$ citizenscienceglobal.org/

${ }^{40} \mathrm{https}$ ://www.gbif.org/

${ }^{41}$ https://www.tdwg.org/

${ }^{42} \mathrm{https}$ ://www.opengeospatial.org/
} 
This is primarily due to the diversity and potentially large extent of projects to which these standards could apply. We still lack an effective and efficient way to not only disseminate related information but also to support the community in the use of standards - which all too often require some highly specific skills and capacities, even to digest the essential requirements.

A further important area for improvement considers data management and processing - especially when it comes to private data. A milestone was reached on the $25^{\text {th }}$ of May 2018, when the European Union's General Data Protection Regulation (GDPR) ${ }^{43}$ came into force. As an essential part of a broader data protection framework, this globally recognized legal act protects and empowers all EU citizens' data privacy, and it also inspired similar discussions outside the EU. This still very recent regulation - with very few legal cases supporting its interpretation - also challenges the citizen science community because it requests clarity and security for treating information, which is indeed very often collected and processed as part of citizen science activities (Berti Suman and Pierce, 2018). Again, guidance and tools remain rare - or at least they are rarely distributed across citizen science projects.

Last but not least, the re-gained interest in Artificial Intelligence (AI) indicates both a future direction and challenge to citizen science. Paired with the unprecedented data collection of humans and machines, as well as the power of new technologies, the interest in AI has a revival in a social-technical setting that could be hardly predicted when AI was born in the 1970s. The potential blends of human cognitive capabilities with machine learning and reasoning when sensibly combined - promise to be powerful in creating new insights and scientific knowledge. Citizens are likely to be involved in several of these emerging new scientific endeavours. Apart from overall ethical considerations, issues related to the internal workings of algorithms, the transparent use of personal data, and the possible implications of algorithmic biases are most challenging for future citizen science actions.

All of the positive implications coming from citizen science to recent research approaches, however, should be seen with limitations coming from the different natures of scientific disciplines. As examples, we could point to limited usage of citizen science in medical research, in research covering ethical issues, in environmental risk assessments, in genetically modified crops research, etc.

\section{Conclusions}

Citizen science has become an emerging topic among methodological approaches in many research fields. Despite the fact that the practice is very old, the term itself figures in methodological frames more frequently in recent decades. This could be more related to the opening of science, as mentioned by some authors (see e.g. Dörler and Heigl, 2019). Keeping in mind that open science represents also negative phenomena (such as predatory journals), we would consider it as an enabling factor to engage people for scientific activities.

Throughout the world the number of citizen science approaches is increasing - this has led to more coordination of the initiatives and several associations were founded. Under the framework of global partnership and networking,

43 https://eugdpr.org/ many research projects dealing with citizen science issues, whether researching citizen science as such, or using citizen science as a key tool to address a specific problem in various research projects.

Geography as a discipline, albeit with an old tradition, also deals with citizen science. We investigated the occurrence of citizen science in the articles covered by the largest scientific database - WOS. Aware of the limitations associated with the searching methods, our research showed that citizen science in Geography is not fully utilized. Its potential, however, is very high, as can be seen from the number of geographical projects using citizen science as a research approach (including flagship geographical projects such as OpenStreetMap).

Turning to the outputs from citizen science activities, we should also point to the great advantages of collected open data, not only for research but also for policy making, as well as education, etc. As an example, in an OpenStreetMap project, many cities produce their own maps (touristic maps, traffic maps, cycling maps, etc.) based on a freely available database of this spatial data source. Furthermore, data from observing nature (in many ways) can be utilized for biodiversity conservation, etc.

A number of issues related to citizen science have not been discussed in this article. We mentioned only briefly the limited usage of citizen science in some fields (e.g., medical research), but we also did not broadly discuss data quality issues and did not fully touch other aspects of citizen science like citizen motivations, the changing role of educational systems under the open science umbrella, etc. Our reflections in this paper, however, should point to an emerging topic, which needs further discussion with respect to its full adaptation in standard research approaches.

\section{Acknowledgements}

This article was elaborated in the scope of the COST Action "Citizen Science to promote creativity, scientific literacy, and innovation throughout Europe" (CA15212) and the national INTER-COST project "Geographical aspects of Citizen Science: mapping trends, scientific potential and societal impacts in the Czech Republic" (No. LTC18067).

\section{References:}

ALBAGLI, S., MACIEL, M., ABDO, A. (2015): Open Science, open issues. Rio de Janeiro, Unirio.

BADEN, T, CHAGAS, A. M., GAGE, G., MARZULLO, T., PRIETO-GODINO, L., EULER, T. (2015): Open Labware: 3-DPrinting Your Own Lab Equipment. PLOS Biology, 13(3): e1002086.

BARTLING, S., FRIESIKE, S. (2014): Opening Science: The Evolving Guide on How the Internet is Changing Research, Collaboration and Scholarly Publishing. Cham, Springer International Publishing.

BERTI SUMAN, A. PIERCE, R. (2018): Challenges for citizen science and the EU open science agenda under the GDPR. European Data Protection Law Review, 4(3): 284-295.

BIO INNOVATION SERVICE (2018): Citizen science for environmental policy: development of an EU-wide inventory and analysis of selected practices. Final report for the European Commission, DG Environment under the contract 070203/2017/768879/ETU/ENV.A.3, 
in collaboration with Fundacion Ibercivis and The Natural History Museum. Luxembourg: Publications Office of the European Union.

BONNEY, R., COOPER, C. B., DICKINSON, J., KELLING, S., PHILLIPS, T., ROSENBERG, K. V., SHIRK, J. (2009): Citizen science: a developing tool for expanding science knowledge and scientific literacy. BioScience, 59: 977-984.

CAPINERI, C., HAKLAY, M., HUANG, H., ANTONIOU, V., KETTUNEN, J., OSTERMANN, F., PURVES, R. (2016): European Handbook of Crowdsourced Geographic Information. London, Ubiquity Press.

CONNORS, J. P., LEI, S., KELLY, M. (2012): Citizen science in the age of neogeography: Utilizing volunteered geographic information for environmental monitoring. Annals of the Association of American Geographers, 102(6): 1267-1289.

COOPER, A., COETZEE, S., KOURIE, D. (2017): Volunteered geographical information, crowdsourcing, citizen science and neogeography are not the same. Proceedings of the International Cartographic Association, 1: 1-8.

DAVID, P. A. (2008): The Historical Origins of'Open Science': an essay on patronage, reputation and common agency contracting in the scientific revolution. Capitalism and Society, 3(2).

DEVICTOR, V., WHITTAKER, R. J., BELTRAME, C. (2010): Beyond scarcity: citizen science programmes as useful tools for conservation biogeography. Diversity and Distributions, 16(3): 354-362.

DICKINSON, J. L., SHIRK, J., BONTER, D., BONNEY, R., CRAIN, R. L., MARTIN, J., PHILLIPS, T., PURCELL, K. (2012): The current state of citizen science as a tool for ecological research and public engagement. Frontiers in Ecology and the Environment, 10(6): 291-297.

DÖRLER, D., HEIGL. F. (2019): Citizen Science in Österreich. Mitteilungen Der Vereinigung Österreichischer Bibliothekarinnen Und Bibliothekare. [online first] 72(2). Doi: 10.31263/voebm.v72i2.2836

DROEGE, S. (2007): Just Because You Paid Them Doesn't Mean Their Data Are Better. In: McEver, C. et al. [eds.]: Citizen Science Toolkit Conference. (pp. 13-26). Ithaca, NY, Cornell Laboratory of Ornithology.

DUŽÍ, B., OSMAN, R., LEHEJČEK, J., NOVÁKOVÁ, E., TARABA, P., TROJAN, J. (2019): Exploring citizen science in post-socialist space: Uncovering its hidden character in the Czech Republic. Moravian Geographical Reports, 27(4): 241-253.

ECSA (2015): Ten principles of citizen science [online]. Available at: https://ecsa.citizen-science.net/sites/default/ files/ecsa_ten_principles_of_citizen_science.pdf

EITZEL, M., CAPPADONNA, J., SANTOS-LANG, C., DUERR, R., WEST, S. E., VIRAPONGSE, A., KYBA, C., BOWSER, A., COOPER, C., SFORZI, A., METCALFE, A. (2017): Citizen science terminology matters: Exploring key terms. Citizen Science: Theory and Practice, 2(1): $1-20$

FELL, M. J. (2019): The Economic Impacts of Open Science: A Rapid Evidence Assessment. Publications, 7(3): 46.
FOLLETT, R., STREZOV, V. (2015): An analysis of citizen science based research: usage and publication patterns. PloS one, 10(11): e0143687.

FOODY, G., SEE, L., FRITZ, S., MOONEY, P., OLTEANURAIMOND, A.-M., FONTE, C.C., ANTONIOU, V. (2017): Mapping and the Citizen Sensor. London, UK, Ubiquity Press.

FOSTER (2016): Fostering the practical implementation of Open Science in Horizon 2020 and beyond. Foster Plus Project Website [online]. Available at: https://www. fosteropenscience.eu

FRIESIKE, S. (2014): Creative Commons Licences. In: Bartling S., Friesike S. [eds.]: Opening Science (pp. 287288). Cham, Springer.

GADERMAIER, G., DÖRLER, D., HEIGL, F., MAYR, S., RÜDISSER, J., BRODSCHNEIDER, R., MARIZZI, C. (2018): Peer-reviewed publishing of results from Citizen Science projects. Journal of Science Communication, 17(3): L01.

GOODCHILD, M. (2007): Citizens as sensors: the world of volunteered geography. GeoJournal, 69(4): 211-221.

GREEN, S. (2017): An Illustrated History of Open Science [online]. Available at: https://www.wiley.com/network/ societyleaders/open-science/an-illustrated-history-ofopen-science

HADJ-HAMMOU, J., LOISELLE, S., OPHOF, D., THORNHILL, I. (2017): Getting the full picture: Assessing the complementarity of citizen science and agency monitoring data. PloS One, 12(12): e0188507.

HAKLAY, M. (2013): Citizen science and volunteered geographic information: Overview and typology of participation. In: Sui, D., Elwood, S., Goodchild, M. [eds.]: Crowdsourcing geographic knowledge (pp. 105122). Dordrecht, Springer.

HAKLAY, M., WEBER, P. (2008): Openstreetmap: Usergenerated street maps. IEEE Pervasive Computing, 7(4): $12-18$

HECKER, S., HAKLAY, M., BOWSER, A., MAKUCH, Z., VOGEL, J., BOON, A. (2018): Citizen Science: Innovation in Open Science, Society and Policy. London, UCL Press.

IRWIN, A. (1995): Citizen Science: A Study of People, Expertise, and Sustainable Development. London and New York, Routledge.

KERSKI， J. J. (2015): Geo-awareness, geo-enablement, geotechnologies, citizen science, and storytelling: Geography on the world stage. Geography Compass, 9(1): $14-26$

KULLENBERG, C., KASPEROWSKI, D. (2016): What is citizen science? A scientometric meta-analysis. PloS one, 11(1): $\mathrm{e} 0147152$

LESZCZYNSKI, A. (2014): On the neo in neogeography. Annals of the Association of American Geographers, 104(1): 60-79.

MEASHAM, T. G. (2007): Building capacity for environmental management: local knowledge and rehabilitation on the Gippsland Red Gum Plains. Australian Geographer, 38(2): 145-159.

MIMS, F. M. (1999): Amateur Science - StrongTradition, Bright Future. Science, 284(5411): 55-56. 
MIROWSKI, P. (2018): The future(s) of open science. Social Studies of Science, 48(2): 171-203.

ODENWALD, S. (2018): A Citation Study of Citizen Science Projects in Space Science and Astronomy. Citizen Science: Theory and Practice, 3(2): 5-10.

PEARCE, J. (2012): Building Research Equipment with Free, Open-Source Hardware. Science, 337(6100): 1303-1304.

SCHADE, S., MANZONI BRUSATI, M., TSINARAKI, C., KOTSEV, A., FULLERTON, K., SGNAOLIN, R., SPINELLI, F. and MITTON, I. (2017a): Using new data sources for policymaking. Luxembourg, Publications Office of the European Union.

SCHADE, S., TSINARAKI, C., ROGLIA, E. (2017b): Scientific data from and for the citizen. First Monday, 22(8).

SOROKOWSKI, P., KULCZYCKI, E., SOROKOWSKA, A., PISANSKI, K. (2017): Predatory journals recruit fake editor. Nature, 543(7646): 481.
SUI, D., ELWOOD, S., GOODCHILD, M. (2012): Crowdsourcing geographic knowledge: volunteered geographic information (VGI) in theory and practice. Dordrecht, Springer Science \& Business Media.

THEOBALD, E. J. et al. (2015): Global change and local solutions: Tapping the unrealized potential of citizen science for biodiversity research. Biological Conservation, 181: 236-244.

TURNER, A. (2006): Introduction to neo-geography. Sebastopol, CA, O'Reilly Media, Inc.

WILKINSON, M. D., DUMONTIER, M., AALBERSBERG, I. J., APPLETON, G., AXTON, M., BAAK, A., MONS, B. (2016): The FAIR Guiding Principles for scientific data management and stewardship. Scientific Data, 3: 1-9.

WILSON, M. W., GRAHAM, M. (2013): Situating Neogeography. Environment and Planning A: Economy and Space, 45(1): 3-9.

\section{Please cite this article as:}

TROJAN, J., SCHADE, S., LEMMENS, R., FRANTÁL, B. (2019): Citizen science as a new approach in Geography and beyond: Review and reflections. Moravian Geographical Reports, 27(4): 254-264. Doi: 10.2478/mgr-2019-0020. 